\title{
Lipophilic Arginine Esters: The Gateway to Preservatives without Side Effects
}

\author{
Iram Shahzadi, Aamir Jalil, Mulazim Hussain Asim, Andrea Hupfauf, Ronald Gust, \\ Philipp Alexander Nelles, Ludwig Knabl, and Andreas Bernkop-Schnürch*
}

Cite This: Mol. Pharmaceutics 2020, 17, 3129-3139

Read Online

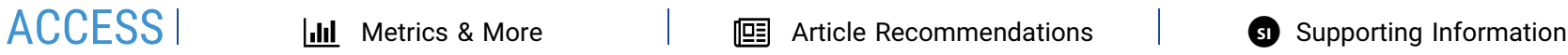

ABSTRACT: This study hypothesized that long carbon chain cationic arginine (Arg) esters can be considered as toxicologically harmless preservatives. Arg-esters with $\mathrm{C}_{18}$ and $\mathrm{C}_{24}$ carbon chains, namely, arginine-oleate (Arg-OL) and arginine-decyltetradecanoate (Arg-DT), were synthesized. Structures were confirmed by FT-IR, ${ }^{1} \mathrm{H}$ NMR, and mass spectroscopy. Both Arg-esters were tested regarding hydrophobicity in terms of $\log P_{\text {octanol/water }}$ critical micelle concentration (CMC), biodegradability, cytotoxicity, hemolysis, and antimicrobial activity against Escherichia coli (E. coli), Staphylococcus aureus (S. aureus), Bacillus subtilis (B. subtilis), and Enterococcus faecalis (E. faecalis). Log $P_{\text {octanol/water }}$ of arginine was raised from -1.9 to 0.3 and 0.6 due to the attachment of $C_{18}$ and $\mathrm{C}_{24}$ carbon chains, respectively. The critical micelle concentration of Arg-OL and Arg-DT was 0.52 and $0.013 \mathrm{mM}$, respectively. Both Arg-esters were biodegradable by porcine pancreatic lipase. In comparison to the well-established antimicrobials, benzalkonium chloride (BAC) and cetrimide, Arg-esters showed significantly less

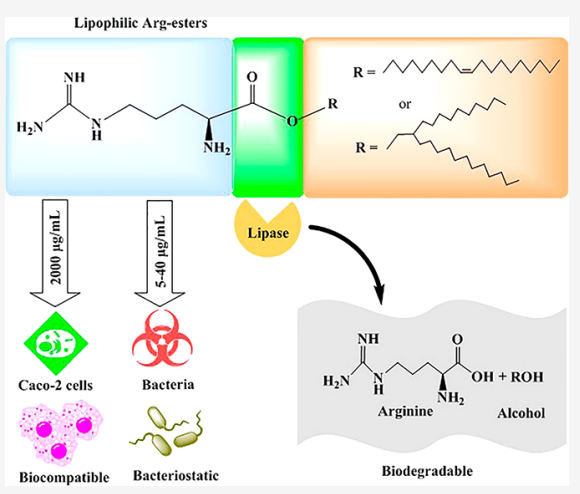
cytotoxic and hemolytic activity. Both esters exhibited pronounced antimicrobial properties against Gram-positive and Gramnegative bacteria comparable to that of $\mathrm{BAC}$ and cetrimide. The minimum inhibitory concentration (MIC) of Arg-esters was $<50 \mu \mathrm{g}$ $\mathrm{mL}^{-1}$ against all tested microbes. Overall, results showed a high potential of Arg-esters with long carbon chains as toxicologically harmless novel preservatives.

KEYWORDS: arginine, antimicrobials, biodegradable, cytotoxicity, hemolysis, minimum inhibitory concentration (MIC), preservatives

\section{INTRODUCTION}

Many cationic lipophilic compounds such as benzalkonium chloride (BAC), cetrimide, and chlorhexidine are used as antiseptics and preservatives because of their excellent

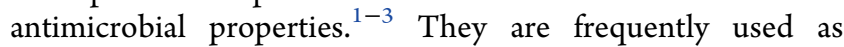
preservatives in topical formulations for dermal, intraoral, ocular, or nasal applications. Although they show antimicrobial action against a broad range of microbes including Grampositive and Gram-negative bacteria, viruses, and yeast, their usefulness remains questionable because of safety concerns. ${ }^{4}$ There are numerous studies reporting about the adverse effects of BAC, cetrimide, and chlorhexidine. ${ }^{5-10}$

The design of preservatives that are stable in the formulation but are immediately degraded when getting into contact with the human body might be a promising concept to address this dilemma. In particular, the introduction of substructures in preservatives that are cleavage sites for endogenous enzymes should guarantee their rapid inactivation and elimination right after application.

As guanidine groups also found in chlorhexidine exhibit in conjunction with lipophilic substructures strong antimicrobial properties, arginine seems to be an excellent starting compound to generate lipophilic cationic agents of high antimicrobial activity. The positive charge on arginine is useful to improve interaction with the negatively charged bacterial cell membranes. Lipophilic substructures that are linked to arginine via ester bond formation might be cleaved by esterases in the human body. The hydrolysis of other compounds containing an ester linkage such as oseltamivir, methylphenidate, and prasugrel by mammalian carboxylesterases is reported in the literature. ${ }^{11}$ Stinchcomb et al. observed complete hydrolysis of lipophilic alkyl esters of naltrexone by esterases on passing through the human skin. ${ }^{12}$

Antimicrobial activity of some other amino acid-based compounds with small and medium fatty chains has already been reported in the literature. Lipophilic derivatives of the cationic amino acid lysine, for instance, were shown to exhibit antimicrobial action against a broad range of bacteria. ${ }^{13}$ In another study, the antimicrobial activity of leucine- and methionine-based esters was shown against bacteria and yeast. ${ }^{14}$ Encouraged by these results, we synthesized arginine

Received: June 8, 2020

Revised: June 28, 2020

Accepted: June 29, 2020

Published: June 29, 2020

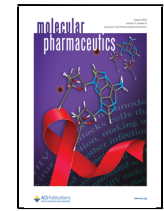


esters with $\mathrm{C}_{18}$ and $\mathrm{C}_{24}$ carbon chains, namely, arginine-oleate and arginine-decyltetradecanoate esters (Arg-OL and ArgDT). Oleyl alcohol was chosen because of its monounsaturated hydrophobic tail, providing a comparatively bulky lipophilic group, and 2-decyl-1-tetradecanol was chosen because of its branched lipophilic structure. The newly synthesized Argesters were initially evaluated regarding $\log P_{\text {octanol/water }}$, critical micelle concentration (CMC), biodegradability by lipase, and cytotoxicity on Caco-2 and red blood cells. Furthermore, their antimicrobial properties against Gram-positive and Gramnegative bacteria were tested to assess their potential use as preservatives for pharmaceutical and cosmetic applications.

\section{MATERIALS AND METHODS}

2.1. Materials. L-Arginine $\geq 98 \%$, oleyl alcohol (9octadecen-1-ol, 85\%), 2-decyltetradecan-1-ol-(2-decyl-1-tetradecanol, 97\%), pyrene, 4-dimethylamino pyridine ( $N, N$ dimethylpyridin-4-amine, DMAP, 99\%), 2,4,6-trinitrobenzenesulfonic acid $(5 \%(\mathrm{~m} / \mathrm{v})$ TNBS solution), sodium dodecyl sulfate (SDS), potassium permanganate, lipase from porcine pancreas, and flat-bottomed 96-well tissue plates were obtained from Sigma-Aldrich $\mathrm{GmbH}$, Austria. Boc- $\operatorname{Arg}(\mathrm{Boc})_{2}-\mathrm{OH}$ was purchased from Bachem, Switzerland. 1-(3-(Dimethylamino)propyl)-3-ethylcarbodiimide (EDC > 98.0\%) was obtained from TCI Deutschland GmbH. Dichloromethane (DCM) was purchased from Carl Roth $\mathrm{GmbH}$, Germany.

2.2. Methods. 2.2.1. General Synthesis Method. Boc$\operatorname{Arg}(\mathrm{Boc})_{2}-\mathrm{OH}(474.56 \mathrm{mg} ; 1 \mathrm{mmol})$ dissolved in $10 \mathrm{~mL}$ of DCM was combined with DMAP (14.8 mg; $0.12 \mathrm{mmol}$ ) under continuous stirring. Upon cooling in an ice water bath, a solution of EDC (161.44 mg; $1.04 \mathrm{mmol})$ in $2 \mathrm{~mL}$ of DCM was slowly added. After $30 \mathrm{~min}$, the respective alcohol (1.2 $\mathrm{mmol}$ ) in $5 \mathrm{~mL}$ of DCM was supplemented dropwise, and the mixture was allowed to equilibrate to room temperature. After stirring for an additional $12 \mathrm{~h}$, the solvent was removed under low pressure using a rotary evaporator (Heidolph instrument $\mathrm{GmbH} \& \mathrm{Co}$, Schwabach, Germany).

The purity of the product was determined by thin-layer chromatography (TLC) using an aluminum sheet precoated with silica gel as a stationary phase and ethyl acetate/ petroleum ether $(2: 3, \mathrm{v} / \mathrm{v})$ as a mobile phase. The detection reagent was prepared by dissolving potassium permanganate $(0.5 \mathrm{~g})$ and potassium carbonate $(3.3 \mathrm{~g})$ in water $(50 \mathrm{~mL})$, followed by the addition of $1 \mathrm{~mL}$ of $1 \mathrm{M} \mathrm{NaOH}$. After spraying with the detection reagent, the TLC plate was heated to obtain yellow spots.

Purification of the products was performed by column chromatography using silica gel $(40-63 \mu \mathrm{m}$ particle size and $60 \AA$ pore size) as a stationary phase. Ethyl acetate/petroleum ether 2:3 and 1:9 (v/v) was used as mobile a phase for elution of Boc-Arg-OL and Boc-Arg-DT ester, respectively. Eluted fractions were analyzed by TLC as described above. Afterward, the purified products were obtained by evaporating the solvent under a vacuum from selected fractions.

Boc-Protected Octadec-9-en-1-yl Argininate (Boc-Arg$O L)$ : obtained as a colorless oil; yield $=203 \mathrm{mg}(0.28 \mathrm{mmol}$, $28 \%)$.

Purification: TLC and column chromatography = ethyl acetate/petroleum ether $(2: 3 \mathrm{v} / \mathrm{v})$.

${ }^{1} \mathrm{H}$ NMR (400 MHz, $\mathrm{CDCl}_{3}$ ): $\delta 0.86-0.90\left(\mathrm{~m}, 3 \mathrm{H}, \mathrm{CH}_{3}\right)$; $1.22-1.38\left(\mathrm{~m}, 24 \mathrm{H}, \mathrm{CH}_{2}\right) ; 1.44\left(\mathrm{~s}, 9 \mathrm{H}, \mathrm{CH}_{3} \mathrm{Boc}\right) ; 1.50(\mathrm{~s}$, $9 \mathrm{H}, \mathrm{CH}_{3} \mathrm{Boc}$ ); 1.52 (s, 9H, $\left.\mathrm{CH}_{3} \mathrm{Boc}\right) ; 1.58-1.88(\mathrm{~m}, 7 \mathrm{H}$, $\mathrm{NH}, \mathrm{CH}_{2}$ arginine and $\mathrm{CH}_{2} \mathrm{CH}_{2} \mathrm{O}$ oleylalcohol); 1.93-2.05 (m, $\left.4 \mathrm{H}, \mathrm{CH}_{2} \mathrm{CH}=\mathrm{CH}\right) ; 3.80-3.97\left(\mathrm{~m}, 2 \mathrm{H}, \mathrm{NCH}_{2}\right.$ arginine); $4.11\left(\mathrm{td},{ }^{3} \mathrm{~J}=6.8 \mathrm{~Hz},{ }^{4} \mathrm{~J}=2.8 \mathrm{~Hz}, \mathrm{OCH}_{2}\right) ; 4.23-4.33(\mathrm{~m}, 1 \mathrm{H}$, CHN arginine); $5.33-5.40(\mathrm{~m}, 2 \mathrm{H}, \mathrm{CH}=\mathrm{CH}) ; 9.20(\mathrm{br}, 1 \mathrm{H}$, $\mathrm{NH}) ; 9.35$ (br, $1 \mathrm{H}, \mathrm{NH})$.

Boc-Protected Arginine 2-Decyltetradecyl Argininate (Boc-Arg-DT): obtained as colorless oil; yield = $172 \mathrm{mg}$ (0.22 mmol, 22\%).

Purification: TLC and column chromatography = ethyl acetate/petroleum ether $(9: 1 \mathrm{v} / \mathrm{v})$.

${ }^{1} \mathrm{H}$ NMR (400 MHz, $\left.\mathrm{CDCl}_{3}\right): \delta 0.88\left(\mathrm{t},{ }^{3} \mathrm{~J}=6.8 \mathrm{~Hz}, 6 \mathrm{H}\right.$, $\left.\mathrm{CH}_{3}\right) ; 1.20-1.35\left(\mathrm{~m}, 40 \mathrm{H}, \mathrm{CH}_{2}\right) ; 1.44$ (s, 9H, $\left.\mathrm{CH}_{3} \mathrm{Boc}\right) ; 1.50$ (s, 9H, $\left.\mathrm{CH}_{3} \mathrm{Boc}\right) ; 1.52\left(\mathrm{~s}, 9 \mathrm{H}, \mathrm{CH}_{3} \mathrm{Boc}\right) ; 1.58-1.73(\mathrm{~m}, 4 \mathrm{H}$, $\mathrm{CH}_{2}$ arginine); $1.75-1.87\left(\mathrm{~m}, 1 \mathrm{H}, \mathrm{OCH}_{2} \mathrm{CH}\right) ; 3.80-3.97(\mathrm{~m}$, $2 \mathrm{H}, \mathrm{NCH}_{2}$ arginine); $4.02\left(\mathrm{ddd},{ }^{3} \mathrm{~J}=14.8 \mathrm{~Hz},{ }^{3} \mathrm{~J}=10.8 \mathrm{~Hz},{ }^{4} \mathrm{~J}\right.$ $\left.=6.0 \mathrm{~Hz}, 2 \mathrm{H}, \mathrm{OCH}_{2}\right) ; 4.24-4.32(\mathrm{~m}, 1 \mathrm{H}, \mathrm{CHN}$ arginine $)$; $5.37\left(\right.$ br d, $\left.{ }^{3} \mathrm{~J}=8.4 \mathrm{~Hz}, 1 \mathrm{H}, \mathrm{NH}\right) ; 9.19$ (br s, $\left.1 \mathrm{H}, \mathrm{NH}\right) ; 9.35$ (br s, $1 \mathrm{H}, \mathrm{NH}$ ).

2.2.2. Deprotection of the Boc-Arg-OL and Boc-Arg-DT Esters. The respective ester was dissolved in DCM and TFA 1:1 and stirred at $25{ }^{\circ} \mathrm{C}$ for $2 \mathrm{~h}$. The solvent was removed under a vacuum. The product was characterized by FT-IR, ${ }^{1} \mathrm{H}$ NMR, and mass spectroscopy.

Octadec-9-en-1-yl Argininate Trifluoroacetate (Arg-OL): obtained as colorless oil; yield $=150 \mathrm{mg}(0.27 \mathrm{mmol}, 96 \%)$.

FT-IR: $\bar{\nu}=3363 \mathrm{w}(\mathrm{NH}) ; 3187 \mathrm{w}(\mathrm{NH}) ; 2924 \mathrm{~m}\left(\mathrm{CH}_{2}\right)$; $2854 \mathrm{~m}\left(\mathrm{CH}_{2}\right) ; 1744 \mathrm{~m} ; 1667 \mathrm{~s}(\mathrm{C}=\mathrm{O}) ; 1200 \mathrm{~s} ; 1184 \mathrm{~s} ; 1134$ s $(\mathrm{C}-\mathrm{O}) ; 722 \mathrm{~m}$.

${ }^{1} \mathrm{H}$ NMR (400 MHz, CD $\left.\mathrm{OD}\right): \delta 0.87-0.93\left(\mathrm{~m}, 3 \mathrm{H}, \mathrm{CH}_{3}\right)$; 1.26-1.42 (m, 24H, $\left.\mathrm{CH}_{2}\right)$; $1.64-2.08\left(\mathrm{~m}, 8 \mathrm{H}, \mathrm{CH}_{2} \mathrm{CH}_{2} \mathrm{O}\right.$, $\mathrm{CH}_{2}$ arginine, $\left.\mathrm{CH}_{2} \mathrm{CH}=\mathrm{CH}\right) ; 3.25\left(\mathrm{t},{ }^{3} \mathrm{~J}=6.8 \mathrm{~Hz}, 2 \mathrm{H}, \mathrm{NCH}_{2}\right.$ arginine $) ; 4.08\left(\mathrm{t},{ }^{3} \mathrm{~J}=6.4 \mathrm{~Hz}, 1 \mathrm{H}, \mathrm{CHN}\right) ; 4.26\left(\mathrm{td},{ }^{3} \mathrm{~J}=6.8\right.$ $\left.\mathrm{Hz},{ }^{4} \mathrm{~J}=2.8 \mathrm{~Hz}, 2 \mathrm{H}, \mathrm{OCH}_{2}\right) ; 5.30-5.42(\mathrm{~m}, 2 \mathrm{H}, \mathrm{CH}=\mathrm{CH})$. MS: 425.3876 (predicted: $425.38[\mathrm{M}+\mathrm{H}]^{+}$).

2-Decyltetradecyl Argininate Trifluoroacetate (Arg-DT): obtained as a colorless oil; yield $=148 \mathrm{mg}(0.21 \mathrm{mmol}, 95 \%)$.

FT-IR: $\bar{\nu}=3394 \mathrm{w}(\mathrm{NH}) ; 3185 \mathrm{w}(\mathrm{NH}) ; 2953 \mathrm{~m}\left(\mathrm{CH}_{2}\right)$; $2922 \mathrm{~s}\left(\mathrm{CH}_{2}\right) ; 2853 \mathrm{~m}\left(\mathrm{CH}_{2}\right) ; 1674 \mathrm{~s}(\mathrm{C}=\mathrm{O}) ; 1633 \mathrm{~m}(\mathrm{C}=$ $\mathrm{N})$; $1201 \mathrm{~s} ; 1185 \mathrm{~s} ; 1137 \mathrm{~s}(\mathrm{C}-\mathrm{O})$.

${ }^{1} \mathrm{H}$ NMR (400 MHz, $\left.\mathrm{CD}_{3} \mathrm{OD}\right): \delta 0.87-0.93\left(\mathrm{~m}, 6 \mathrm{H}, \mathrm{CH}_{3}\right)$; 1.24-1.38 (m, 40H, $\left.\mathrm{CH}_{2}\right) ; 1.65-1.85\left(\mathrm{~m}, 3 \mathrm{H}, \mathrm{OCH}_{2} \mathrm{CH}\right.$ and $\mathrm{CH}_{2}$ arginine); $1.88-2.08\left(\mathrm{~m}, 2 \mathrm{H}, \mathrm{CH}_{2} \mathrm{CH}\right.$ arginine $) ; 3.24(\mathrm{t}$, ${ }^{3} \mathrm{~J}=7.0 \mathrm{~Hz}, 2 \mathrm{H}, \mathrm{CH}_{2} \mathrm{~N}$ arginine $) ; 4.10\left(\mathrm{t},{ }^{3} \mathrm{~J}=6.4 \mathrm{~Hz}, 1 \mathrm{H}\right.$, CHN arginine); 4.19 (ddd, ${ }^{3} \mathrm{~J}=13.4 \mathrm{~Hz},{ }^{3} \mathrm{~J}=10.8 \mathrm{~Hz},{ }^{4} \mathrm{~J}=5.6$ $\mathrm{Hz}, 2 \mathrm{H}, \mathrm{OCH}_{2}$ ).

MS: 511.4987 (predicted: $511.49[\mathrm{M}+\mathrm{H}]^{+}$).

2.2.3. Characterization. FT-IR spectra were taken on a Bruker ALPHA FT-IR equipped with a Platinum ATR sampling module and analyzed with OPUS Spectroscopy Software, version 7. FT-IR spectra were recorded at a resolution of $4 \mathrm{~cm}^{-1}$ in the wavenumber range from $4000-$ $400 \mathrm{~cm}^{-1}$ with 24 scans.

${ }^{1} \mathrm{H}$ NMR spectra were measured on a Bruker Avance 4 Neo spectrometer at $400.13 \mathrm{MHz}$. The center of the solvent signal was used for calibration, or the TMS (tetramethylsilane) signal acted as an internal standard. The samples were dissolved in $\mathrm{CDCl}_{3}$ or $\mathrm{CD}_{3} \mathrm{OD}$ (Eurisotop).

Mass spectra were recorded on a Thermo Fisher Orbitrap Elite, equipped with an ESI ion source.

2.2.4. Determination of $\log P$. Log $P$ of Arg and both Argesters were determined using an already described method. ${ }^{\text {is }}$ Each compound was dissolved in an octanol/water mixture $(1: 1, \mathrm{v} / \mathrm{v})$. Afterward, octanol and water phases were separated by a high-speed mini centrifuge (Fisher Scientific, Illinois 
USA), and the concentration of each compound in each phase was determined by the TNBS assay. For this, a $50 \mu \mathrm{L}$ volume from each phase was diluted 10 times with $0.1 \mathrm{M}$ sodium bicarbonate $(\mathrm{pH} 8.5)$ containing $40 \%(\mathrm{v} / \mathrm{v})$ isopropyl alcohol. After dilution, $250 \mu \mathrm{L}$ of the TNBS reagent $(0.01 \%, \mathrm{v} / \mathrm{v})$ prepared in $0.1 \mathrm{M}$ sodium bicarbonate $(\mathrm{pH} 8.5)$ was added to each sample that was incubated at $37{ }^{\circ} \mathrm{C}$. After $2 \mathrm{~h}$, the reaction was stopped by adding $250 \mu \mathrm{L}$ of $10 \%(\mathrm{~m} / \mathrm{v})$ SDS and $125 \mu \mathrm{L}$ of $1 \mathrm{M} \mathrm{HCl}$. The absorbance of each sample was measured at $335 \mathrm{~nm}$ using a Spark multifunctional microplate reader (Tecan Austria, GmbH). The logarithm of the octanol/ water absorbance ratio was expressed as $\log P$ for each sample.

2.2.5. Determination of the CMC. The critical micelle concentration (CMC) is an important solution property of any amphiphilic compound and can be defined as the minimum concentration at which micelles start to form. The CMC of Arg-esters was determined using a pyrene fluorescent method as described in a previous publication. ${ }^{15}$ Methanol solution of pyrene $(2 \mu \mathrm{M})$ was added to several vials $(250 \mu \mathrm{L}$ per vial $)$ and evaporated overnight to leave thin dried films of pyrene. Aqueous solutions of Arg-esters were prepared in a wide concentration range and were added to individual vials containing pyrene films in a $500 \mu \mathrm{L}$ volume. The samples were left stirring at $400 \mathrm{rpm}, 37^{\circ} \mathrm{C}$. After $3 \mathrm{~h}$, the fluorescence of each sample was measured at the excitation wavelength of $334 \mathrm{~nm}$, and emissions were taken at $372\left(I_{1}\right) \mathrm{nm}$ and $393 \mathrm{~nm}$ $\left(I_{3}\right)$. A graph was plotted between the fluorescent intensity ratio $\left(I_{3} / I_{1}\right)$ and the log concentration of Arg-ester. Then, from the resulting curve for each Arg-ester, the "CMC value" was calculated. For the calculation of the CMC, the segmental linear regression method was used, and $\mathrm{CMC}$ values were obtained as the concentration corresponding to the intercept of the extrapolations of the first segment and the rapidly varying second segment of the $I_{3} / I_{1}$ versus log concentration plot. The following equation was used for determining the CMC:

$$
\log \mathrm{CMC}=\frac{\text { intercept } 1-\text { intercept } 2}{\text { slope } 2-\text { slope } 1}
$$

where values of intercept and slope 1 were taken from the equation of the straight line of segment 1 and intercept and slope 2 were taken from the equation of the straight line of segment 2 of each plot.

2.2.6. Degradation of Arginine Esters by Lipase. Lipasecatalyzed hydrolytic degradation of Arg-OL and Arg-DT esters was carried out using a previously described experimental setup. ${ }^{16}$ Digestion medium consisted of $2 \mathrm{mM}$ Tris buffer with $5 \mathrm{mM} \mathrm{CaCl} 2$ and $150 \mathrm{mM} \mathrm{NaCl}$. The medium $\mathrm{pH}$ was adjusted to 6.8. Lipase solution was freshly prepared before the experiment as follows: $0.5 \mathrm{~g}$ of lipase was mixed for $10 \mathrm{~min}$ in $10 \mathrm{~mL}$ of digestion medium, followed by centrifugation at $12000 \mathrm{rpm}$ and $4{ }^{\circ} \mathrm{C}$ for $15 \mathrm{~min}$. The supernatant was collected for the degradation test and ice-stored until use. For the degradation test, solutions of Arg-OL and Arg-DT were prepared in the concentration of $1 \mathrm{mM}$ in digestion buffer, and the $\mathrm{pH}$ was adjusted to 6.8 using $0.5 \mathrm{M} \mathrm{NaOH}$. Thereafter, 2 $\mathrm{mL}$ of lipase solution was added to $18 \mathrm{~mL}$ of the Arg-surfactant solution to initiate ester degradation under continuous stirring at $37^{\circ} \mathrm{C}$. The ester hydrolysis was reflected by monitoring the drop in $\mathrm{pH}$ due to the release of arginine and titrated to keep the $\mathrm{pH}$ at 6.8 with the addition of $0.5 \mathrm{M} \mathrm{NaOH}$. The experiment was continued for $3 \mathrm{~h}$. Back-titration was also performed at the end of the experiment by raising the $\mathrm{pH}$ to 9 , and additional consumption of the $\mathrm{NaOH}$ volume reflected the nonionized form of an amino acid. Degradation and backtitrations were also performed using a blank digestion medium without any Arg-ester, and consumed $\mathrm{NaOH}$ volume was subtracted from that consumed for each product. Consumed volumes of $0.5 \mathrm{M} \mathrm{NaOH}$ for each product were then equated with liberated free arginine to determine the percentage of arginine esters digested. Degradation was also confirmed at the end of the experiment by TLC using an aluminum sheet precoated with silica gel and acetic acid/chloroform/methanol $(5: 8.5: 10, \mathrm{v} / \mathrm{v} / \mathrm{v})$ as stationary and mobile phases, respectively. The TLC plate after spraying with a ninhydrin ethanolic solution $(0.2 \%, \mathrm{~m} / \mathrm{v})$ was heated to visualize products as purple spots.

2.2.7. Resazurin Assay. The resazurin assay was used to determine the cytotoxic potential of Arg-esters according to a previous method with some minor modifications. ${ }^{15}$ Caco-2 cells were seeded in a 24-well cell culture plate at 25000 cells per well density and kept in an incubator at $37{ }^{\circ} \mathrm{C}$ under a $95 \%$ relative humidity environment and $5 \% \mathrm{CO}_{2}$ level. Minimum essential medium (MEM) supplemented with streptomycin $\left(0.1 \mathrm{mg} \mathrm{L}^{-1}\right)$, penicillin $\left(100\right.$ units $\left.\mathrm{L}^{-1}\right)$, and fetal calf serum (FCS) $10 \%(\mathrm{v} / \mathrm{v})$ was used for growing cells. During a growth period of 14 days, the medium was replaced every other day. On the day of the experiment, test solutions of Arg-OL and Arg-DT esters were prepared in $25 \mathrm{mM}$ HBS (HEPES buffered saline) buffer ( $\mathrm{pH} 7.4)$ in the concentration range of 1000$3000 \mu \mathrm{g} \mathrm{mL}^{-1}$. For comparison, the same concentrations of $\mathrm{BAC}$ and cetrimide were also prepared in HBS. HBS without any addition was used as a positive control, and Triton X-100 $(2 \%, v / v)$ in HBS was used as a negative control. The growth medium from all wells of the cell culture plate was removed, and cells were washed three times with HBS preheated at 37 ${ }^{\circ} \mathrm{C}$. Each test solution and controls were then added to individual wells in a volume of $500 \mu \mathrm{L}$, and the cell culture plate was incubated under the same conditions. After $4 \mathrm{~h}$, the solution from each well was removed, and cells were washed with HBS ( $\mathrm{pH} 7.4)$ preheated at $37{ }^{\circ} \mathrm{C}$. Then, $500 \mu \mathrm{L}$ of resazurin $(2.2 \mathrm{mM})$ per well was added and incubated for further $3 \mathrm{~h}$ under the same conditions. Afterward, the fluorescence of the supernatant from each well was measured at the excitation wavelength of $540 \mathrm{~nm}$ and an emission wavelength of $590 \mathrm{~nm}$. Cell viability was calculated by the equation:

$$
\begin{aligned}
& \text { cell viability }(\%) \\
& =\frac{\text { fluorescence }(\text { test })-\text { fluorescence }(\text { negative })}{\text { fluorescence }(\text { positive })-\text { fluorescence (negative) }} \times 100
\end{aligned}
$$

2.2.8. Measurement of Fluorescence Anisotropy. To evaluate membrane fluidity by fluorescence spectroscopy, a method described by Aricha et al. was adapted. ${ }^{17}$ Caco- 2 cells were labeled with fluorescent probe DPH (1,6-diphenyl-1,3,5hexatriene). For this, a $1 \mathrm{mM}$ solution of $\mathrm{DPH}$ was prepared in acetone. A Caco- 2 cell monolayer in a $15 \mathrm{~mL}$ cell flask after washing with sterile PBS was trypsinized and resuspended in $10 \mathrm{mM}$ HBS ( $\mathrm{pH} 7.4)$ at a concentration of $2 \times 10^{5}$ cells $\mathrm{mL}^{-1}$. Then a $1 \mathrm{mM} \mathrm{DPH}$ solution $(10 \mu \mathrm{L})$ was added to a Caco- 2 cell suspension $(5 \mathrm{~mL})$ and kept for incubation at 37 ${ }^{\circ} \mathrm{C}$ in the dark. After $1 \mathrm{~h}$, cells were centrifuged at $588 \mathrm{rpm}$ for $3 \mathrm{~min}$, and solvent was removed to get rid of the free probe. Cells were resuspended in the same volume of HBS. Samples of Arg-surfactants were prepared in HBS in concentrations of 


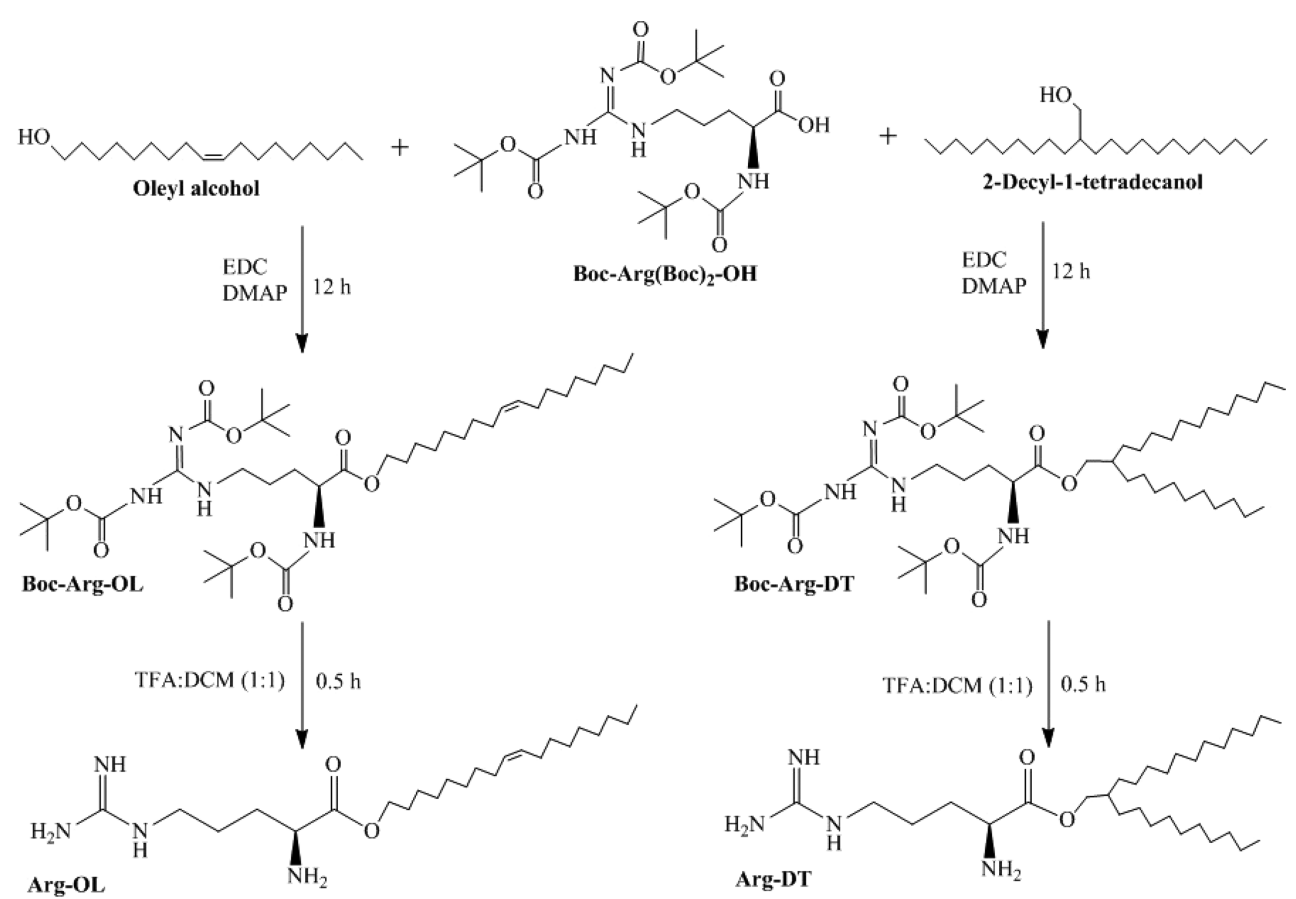

Figure 1. Synthesis of Arg-OL and Arg-DT esters.

2000, 1000, and $500 \mu \mathrm{g} \mathrm{mL}^{-1}$. Then each sample solution was mixed with a DPH-labeled cell suspension in equal volumes and incubated at room temperature in the dark. HBS mixed in an equal volume with the DPH-labeled cell suspension was used as a control. At specific time points, fluorescence polarization data were obtained using an excitation wavelength of $350 \mathrm{~nm}$ and an emission wavelength of $420 \mathrm{~nm}$, and anisotropy was calculated using the following equation:

$$
\text { anisotropy }(r)=\frac{I_{\|}-I_{\perp}}{I_{\|}+2 I_{\perp}}
$$

where $I_{\|}$and $I_{\perp}$ are the fluorescence intensities parallel and perpendicular to the direction of the excitation light beam.

2.2.9. Hemolysis Study. The hemolysis test was performed with red blood cells (RBC) to evaluate the potential toxic effect of Arg-surfactants on human cells. ${ }^{18}$ Human RBC concentrate was kindly donated by the Tirol Kliniken $\mathrm{GmbH}$, Innsbruck, Austria, and stored at $4{ }^{\circ} \mathrm{C}$ until use. RBC concentrate $(0.556 \mathrm{~mL})$ was freshly diluted by adding sterile Dulbecco's PBS ( $\mathrm{pH} 7.4)$ (1.944 mL) before the test to obtain an equivalent amount of whole blood (EWB). Then EWB was 50 times diluted in sterile Dulbecco's PBS ( $\mathrm{pH}$ 7.4). The diluted blood on visual inspection was turbid and settled down upon leaving undisturbed, indicating no cell lysis. Argsurfactant stock solutions were prepared in the concentration range of $10-5000 \mu \mathrm{g} \mathrm{mL}^{-1}$ in PBS. For comparison, BAC and cetrimide solutions were prepared in the same concentration range in PBS. For the assay, $10 \mu \mathrm{L}$ of each test sample was mixed with $190 \mu \mathrm{L}$ of diluted blood, resulting in the testing final concentrations of $0.5-250 \mu \mathrm{g} \mathrm{mL}^{-1}$. For the positive control, $10 \mu \mathrm{L}$ of $20 \% \mathrm{v} / \mathrm{v}$ Triton X-100 and, for the negative control, $10 \mu \mathrm{L}$ of sterile Dulbecco's PBS were mixed with 190 $\mu \mathrm{L}$ of diluted blood. All samples and controls were incubated for $1 \mathrm{~h}$ at $37^{\circ} \mathrm{C}$ with shaking. After centrifugation at 10000 $\mathrm{rpm}$ for $60 \mathrm{~s}$, aliquots of $100 \mu \mathrm{L}$ were withdrawn from the supernatants and transferred to a 96-well plate. Absorbance was measured at a wavelength of $420 \mathrm{~nm}$. The extent of hemolysis as a percentage was determined by using the following equation:

$$
\text { hemolysis }(\%)=\frac{\text { absorbance }(\text { test })-\text { absorbance }(\text { negative })}{\text { absorbance }(\text { positive })-\text { absorbance }(\text { negative })} \times 100
$$

2.2.10. Antimicrobial Properties. Microorganisms. Following bacterial strains were used for antimicrobial susceptibility testing: Escherichia coli ATCC 25922, Staphylococcus aureus ATCC 29213, Bacillus subtilis ATCC 6633, and Enterococcus faecalis ATCC 19433, which were obtained from the American Type Culture Collection (ATCC, Virginia, USA).

Disk Diffusion Method. The disk diffusion method was used for the initial assessment of the antimicrobial activity of Arg-esters. Mueller Hinton agar (MHA, Biomerieux) medium was prepared according to the manufacturer protocol and poured into Petri dishes. All testing microorganisms were dissolved in saline and set to a $0.5 \mathrm{McF}$ arland standard turbidity. This corresponds to a bacterial concentration of 1.5 $\times 10^{8}$ colony-forming units per milliliter $\left(\mathrm{CFU} \mathrm{mL} \mathrm{mL}^{-1}\right)$. The bacterial suspension was then swabbed over solidified MHA Petri dishes ensuring homogeneous distribution. The test solutions of Arg-OL, Arg-DT, BAC, and cetrimide were prepared in water with $10 \%(\mathrm{v} / \mathrm{v})$ DMSO at a concentration of $10 \mathrm{mg} \mathrm{mL}^{-1}$. Water with $10 \%(\mathrm{v} / \mathrm{v})$ DMSO was used as a negative control. The diffusion disks of about $6 \mathrm{~mm}$ in diameter were prepared from Whatman filter paper. After immersing disks in the above-prepared test solutions, they were placed on MHA plates already swabbed with different bacteria. After overnight incubation of Petri dishes at $37^{\circ} \mathrm{C}$, clear zones of bacterial growth inhibition around disks were measured.

Minimum Inhibitory Concentration (MIC) Testing by the Microdilution Method. The MIC is the lowest concentration of a substance that leads to a clearly visible growth inhibition after a defined incubation period. To evaluate the MIC of ArgDT, Arg-OL, BAC, and cetrimide, a microdilution test was 
performed according to the guidelines of the Clinical and Laboratory Standards Institute. ${ }^{19}$ First of all, similarly, as for the disk diffusion test, microorganisms were dissolved in saline and set to a 0.5 McFarland standard turbidity. This corresponds to a bacterial concentration of $1.5 \times 10^{8}$ colonyforming units per milliliter $\left(\mathrm{CFU} \mathrm{mL}{ }^{-1}\right) ; 50 \mu \mathrm{L}$ of the bacterial suspension was added to $10 \mathrm{~mL}$ of Mueller Hinton Bouillon (MHB, Becton Dickinson, New Jersey, USA). The stock solutions were prepared as follows: the test compounds Arg$\mathrm{OL}, \mathrm{Arg}-\mathrm{DT}, \mathrm{BAC}$, and cetrimide were dissolved in water with $10 \%(\mathrm{v} / \mathrm{v})$ DMSO at a concentration of $10 \mathrm{mg} \mathrm{mL}^{-1}$. The obtained solutions were used to prepare serial dilutions. The tested concentration for each substance ranged from 5000 to 5 $\mu \mathrm{g} \mathrm{mL}^{-1}$. Each test sample was added to a flat-bottomed tissue plate well in the volume of $75 \mu \mathrm{L}$. The first well of the tissue plate containing $75 \mu \mathrm{L}$ of water with $10 \%$ (v/v) DMSO instead of any test sample was used as a positive control. Finally, $75 \mu \mathrm{L}$ of the bacterial suspension was added to each well, and the plates were incubated at $37{ }^{\circ} \mathrm{C}$ overnight.

Before measuring the optical density (OD), plates were shaken for $15 \mathrm{~min}$ at $250 \mathrm{rpm}$. The OD was measured using the Bio-Rad 680 microplate reader (Hercules, California, USA) at a wavelength of $490 \mathrm{~nm}$. Inhibition of bacterial growth was defined as a reduction of growth for at least $5 \mathrm{log}$ units. Experiments were performed three times under analogous conditions for each bacterial strain and each tested sample.

2.2.11. Statistical Analysis. GraphPad Prism 5 software was used for data analysis. One-way and two-way ANOVA with the Bonferroni posthoc test were used for statistical comparisons with $P<0.05$ as the minimal level of significance. Data were shown as the mean $\pm \mathrm{SD}$.

\section{RESULTS AND DISCUSSION}

3.1. Synthesis of Lipophilic Arg-Esters. Arg-OL and Arg-DT esters were synthesized by esterification of Bocarginine with long carbon chain alcohols, followed by Boc deprotection. Synthesis and chemical structures of surfactants are shown in Figure 1.

Esterification was confirmed for Boc-Arg-OL, due to the shift of the $\mathrm{O}-\mathrm{CH}_{2}$ signal $(\mathrm{g})$ from $3.64 \mathrm{ppm}$, as shown in the free oleyl alcohol (Figure S-1), toward $4.11 \mathrm{ppm}$ in the BocArg-OL (Figure S-2). The signal (a) at $0.88 \mathrm{ppm}$ was assigned to the terminal methyl protons, while the resonances of the methylene groups $\left((\mathbf{b})\right.$ and $\left.\left(\mathbf{b}^{\prime}\right)\right)$ were located at $1.22-1.38$ ppm. The methylene protons ( $\mathbf{d}$ and $\mathbf{n}$ ) and one $\mathrm{NH}$ proton caused signals in the range of $1.58-1.88 \mathrm{ppm}$. In this region, the signal of the methylene protons (d) within the oleyl residue was also located. The protons $\left(\mathbf{i}, \mathbf{i}^{\prime}\right)$ at the double bond were more deshielded and yield the well-separated superimposed multiplet at $5.33-5.40 \mathrm{ppm}$, which were not shown to be influenced upon esterification. Also, the chemical shifts of e and $\mathrm{e}^{\prime}$ at 1.93-2.05 ppm were unaffected. Characteristic signals of the arginine moiety resulted from the methylene protons (f) next to the nitrogen at about 3.80-3.97 ppm and the methine proton $(\mathrm{h})$ at $4.23-4.33 \mathrm{ppm}$. Furthermore, Bocprotection was confirmed by the singlets $\left(\mathbf{c}, \mathbf{c}^{\prime}\right.$, and $\left.\mathbf{c}^{\prime \prime}\right)$ at 1.44 , 1.50, and $1.52 \mathrm{ppm}$. Broad signals at 9.20 and $9.35 \mathrm{ppm}$ were an indication for $\mathrm{NH}$ protons.

The same trend was observed for Boc-Arg-DT. The $\mathrm{CH}_{2}$ group (g) was characteristically shifted from $3.54 \mathrm{ppm}$ (for free alcohol, see Figure S-3) to $4.02 \mathrm{ppm}$ upon esterification (Figure S-4).
The methine proton ( $j$ ) changed from 1.14-1.18 ppm (alcohol) to $1.75-1.87 \mathrm{ppm}$ (ester). The terminal methyl protons $\left(\mathbf{a}, \mathbf{a}^{\prime}\right)$ showed signals at $0.88 \mathrm{ppm}$, the methylene protons $\left(\mathbf{b}, \mathbf{b}^{\prime}\right)$ at $1.20-1.35 \mathrm{ppm}$. The methylene protons of arginine $(\mathbf{k}, \mathbf{l})$ gave a signal at $1.58-1.73 \mathrm{ppm}$, and the ones next to the nitrogen (f) were located at $3.80-3.97 \mathrm{ppm}$. The methine proton of arginine (h) caused a signal at 4.24-4.32 ppm and the Boc groups at 1.44, 1.50, and $1.52 \mathrm{ppm}$. Additional peaks at 5.37, 9.19, and $9.35 \mathrm{ppm}$ were from the protons attached to the nitrogen.

After deprotection, the IR spectra of Arg-OL (Figure S-5) and Arg-DT (Figure S-6) had peaks of $\mathrm{NH}_{2}$ at 3363-3187 $\mathrm{cm}^{-1}$ and 3394-3185 $\mathrm{cm}^{-1}$, respectively. The missing $\mathrm{OH}$ and $\mathrm{COOH}$ vibrations, as well as the presence of the $\mathrm{C}-\mathrm{O}$ band at 1134 and $1137 \mathrm{~cm}^{-1}$ and the characteristic $\mathrm{C}=\mathrm{O}$ vibration at 1667 and $1674 \mathrm{~cm}^{-1}$, were indications for esterification.

As the solubility of Arg-OL and Arg-DT in $\mathrm{CDCl}_{3}$ was insufficient for ${ }^{1} \mathrm{H}$ NMR spectroscopy, the ${ }^{1} \mathrm{H}$ NMR spectra (Figure S-7 and Figure S-8) were recorded in $\mathrm{CD}_{3} \mathrm{OD}$. In the spectra, the missing signals of the Boc groups confirmed deprotection. Because of the solvent change, the chemical shifts of the protons of the alcohol part slightly changed compared to the precursors, and the amino protons underwent an $\mathrm{NH} / \mathrm{ND}$ exchange. The terminal methyl protons (a, $\mathbf{a}^{\prime}$ ) caused signals at $0.87-0.93 \mathrm{ppm}$ and the methylene protons $\left(\mathbf{b}, \mathbf{b}^{\prime}\right)$ signals at $1.24-1.42 \mathrm{ppm}$. The resonances of the methylene protons next to the nitrogen $(f)$ in the arginine part were now at $3.25 \mathrm{ppm}$ (Arg-OL) and $3.24 \mathrm{ppm}$ (Arg-DT), and the signal of the methine proton (h) was located at $4.08 \mathrm{ppm}$ (Arg-OL) and $4.10 \mathrm{ppm}$ (Arg-DT), respectively. Compared to the Boc-protected compounds, a significant shift was observed (f $\delta=3.80-3.97 ; \mathbf{h} \delta=4.23-4.33$ ). The methylene protons (g) confirming esterification appeared at $4.26 \mathrm{ppm}$ (Arg-OL) and $4.19 \mathrm{ppm}$ (Arg-DT), while they were at 4.11 and $4.02 \mathrm{ppm}$ in the spectra of Boc-Arg-OL and Boc-Arg-DT. A characteristic for Arg-OL is the double bond in the alcohol moiety, with a signal group in the range of 5.30-5.42 ppm, representing the protons $\left(\mathbf{i}, \mathbf{i}^{\prime}\right)$.

Furthermore, the mass spectra of Arg-OL and Arg-DT showed the expected mass, referring to ester formation and deprotection (Figure S-9 and S-10).

3.2. Physiochemical Characterization of Arg-Esters. Hydrophobicity is considered an important physicochemical property as it can affect interactions with different macromolecules, cell membranes, and organelles under physiological conditions. ${ }^{20}$ We evaluated hydrophobicity of free arginine as well as Arg-esters by determining their octanol/water partition coefficients $(\log P)$. The results are illustrated in Figure 2. Log $P$ of arginine was significantly increased $(p<0.05)$ from -1.9 to 0.3 and 0.6 in the case of Arg-OL and Arg-DT ester, respectively. Due to this improvement in $\log P$, more efficient insertion of Arg-surfactants within cell membrane lipid bilayer can be expected.

Arg-esters were also evaluated regarding their surface-active property, which is an important characteristic of surfactants. Surfactants are known to accumulate in solution in the form of micelles that can be evaluated in terms of CMC (critical micelle concentration) using a variety of methods. The increase in carbon chain length increases the hydrophobicity of the surfactant, decreases the CMC, and increases the solubilizing power of surface-active compounds. ${ }^{21}$ The CMC of both Arg-esters was determined via a widely used pyrene method that is based on pyrene solubilization in the 


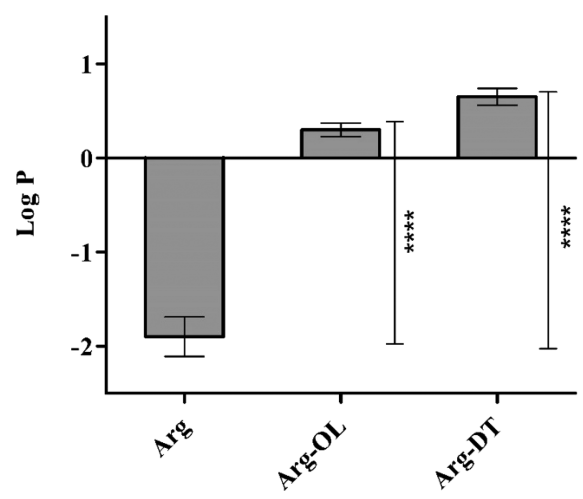

Figure 2. $\log P$ of Arg and Arg-esters. Data represented as the mean $\pm \mathrm{SD}(n=3),(* * * * P<0.0001)$.

hydrophobic core of surfactant micelles. ${ }^{22}$ The results of CMC are depicted in the form of plots in Figure 3. CMC of Arg-OL was found $0.52 \mathrm{mM}$ and of Arg-DT was $0.013 \mathrm{mM}$. It is in agreement with previous studies that $\mathrm{CMC}$ decreases with increasing carbon chain length. ${ }^{23}$
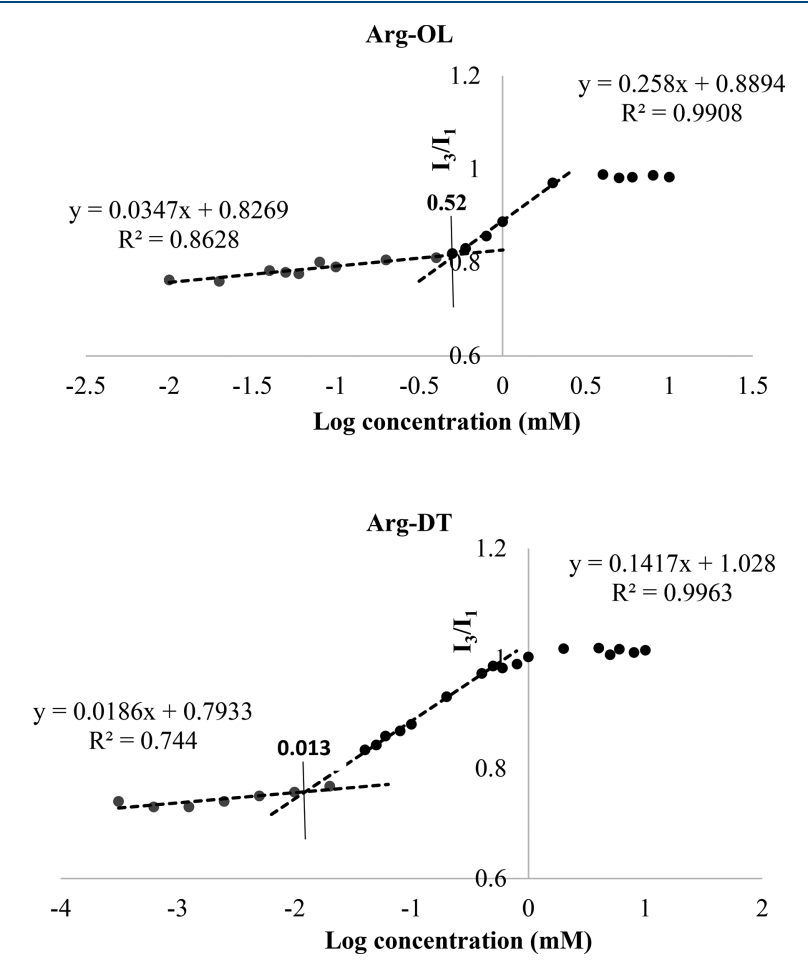

Figure 3. Pyrene intensity ratio $\left(I_{3} / I_{1}\right)$ versus log concentration $(\mathrm{mM})$ plots of Arg-OL and Arg-DT. CMC values in individual plots are denoted by the intersection points of straight lines.

3.3. Biodegradation of Arg-Esters. In the case of wellestablished antimicrobials, a lack of biodegradability is one of the main reasons for their potential toxicity. ${ }^{24,25}$ Biodegradation is an enzyme-catalyzed degradation process and probably one of the most promising strategies for the design of less toxic preservatives. By introducing lipophilic structures in endogenous compounds such as amino acids via labile ester or amide bond formation, relatively fast biodegradation into nontoxic fragments is expected when these conjugates are getting into contact with a high amount of hydrolyzing enzymes in the human body. For degradation studies of the newly developed
Arg-esters, lipase was used as a model enzyme as it is wellknown for hydrolyzing esters. ${ }^{26}$ Moreover, preservatives get into direct contact with this enzyme when they are used in dermal or mucosal products. ${ }^{27,28}$ Furthermore, lipase was already shown to hydrolyze nonionic surfactants containing carbonate, ester, and amide bonds, ${ }^{29}$ as well as to cleave ester bonds in lipophilic lysin esters. ${ }^{30}$ Both Arg-esters were degraded in vitro by lipase into free amino acid and alcohol as illustrated in Figure 4. Cleavage of Arg-esters was confirmed by a constant drop in $\mathrm{pH}$ over time. After $3 \mathrm{~h}, \mathrm{pH}$ change was minor, suggesting almost complete hydrolysis. Within 3 h, 93\% and $85 \%$ of Arg-OL and Arg-DT were cleaved, respectively. Results of TLC confirmed an almost entire cleavage of both esters as neither Arg-OL nor Arg-DT were visible anymore after incubation with lipase as shown in Figure S-11.

The comparatively more rapid biodegradation of Arg-OL than of Arg-DT might be explained by the lower lipophilic character of Arg-OL. Similar results were obtained in a previous study by Pérez et al., where slightly higher biodegradation of single-chain arginine-based surfactants than of double-chain/double-head $\mathrm{N} \alpha, \mathrm{N} \omega$-bis $(\mathrm{N} \alpha$-acylarginine $)$ $\alpha, \omega$-alkylendiamide surfactants was observed. ${ }^{31}$ The biodegradation of Arg-OL and Arg-DT was in the same range as that of other arginine-based compounds reported in the literature such as $\mathrm{N} \alpha$-Acyl-L-arginine methyl ester, arginine- $N$-alkyl amide, and arginine-O-alkyl ester. The authors observed higher biodegradation rates for compounds having an ester bond instead of any other linkage between hydrophobic and hydrophilic moieties. ${ }^{32}$ Tatsumi et al. also observed biodegradability of some cationic Gemini surfactants with an ester linkage and no biodegradation of conjugates with an amide linkage. ${ }^{33}$

As the individual enzyme levels may vary under physiological conditions, however, in vitro biodegradation tests do not mimic the exact in vivo conditions.

3.4. Biocompatibility Studies. Cytotoxicity of lipophilic cationic preservatives is a major concern. Their lipophilic substructures and polar cationic headgroup(s) largely affect their surface properties and toxicological profile. In the case of $\mathrm{N}$-acyl amino acids, it was shown that surface properties are mainly influenced by the carbon chain length, whereas the polar head of amino acid plays an important role in cellular toxicity. ${ }^{34}$ In order to evaluate the toxicity of Arg-OL and ArgDT before degradation, their cytotoxic impact on Caco- 2 cells was studied using the resazurin test. This test is based on the ability to grow cells to reduce nonfluorescent dye (resazurin/ blue) into fluorescent dye (resorufin/pink) measurable by a fluorometer. The resazurin assay is rapid, relatively inexpensive, and more sensitive than the tetrazolium assays. The only drawback is the possibility of fluorescent interference from tested compounds. ${ }^{35}$ The results of this study are shown in Figure 5. Samples showing $>80 \%$ cell viability were considered as nontoxic. BAC and cetrimide serving as reference were found to be highly toxic for Caco- 2 cells with cell viability of $<10 \%$ at all tested concentrations (1000-3000 $\left.\mu \mathrm{g} \mathrm{mL}^{-1}\right)$. In contrast, Arg-esters were found significantly $(p<$ 0.05 ) less cytotoxic at the same concentrations. Arg-OL ester was found cytotoxic at $3000 \mu \mathrm{g} \mathrm{mL}^{-1}$, whereas Arg-DT was noncytotoxic. The comparatively higher toxicity of Arg-OL can be attributed to its likely more intensive interactions with the cell membrane. A similar lysine-based cationic compound hexadecyl lysinate (HL) was noncytotoxic to Caco-2 cells at the higher tested concentration of $250 \mu \mathrm{g} \mathrm{mL}-130$ 

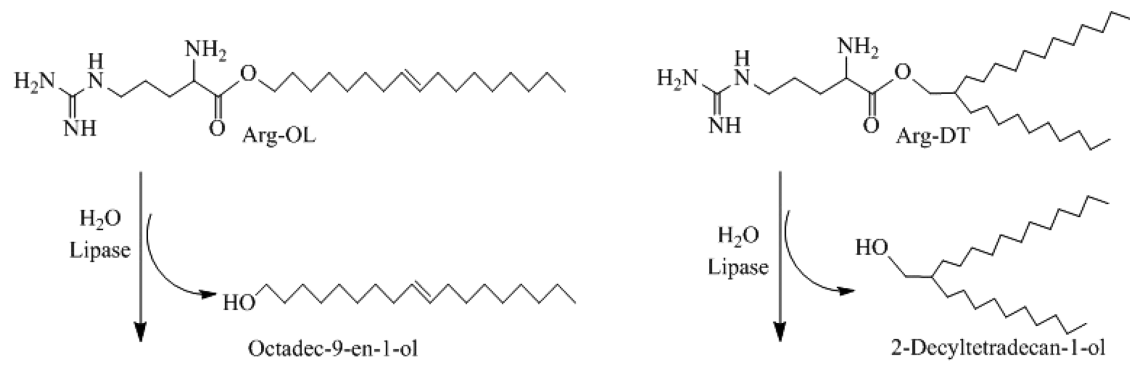<smiles>N=C(N)NCCCC(N)C(=O)O</smiles><smiles>N=C(N)NCCCC(N)C(=O)O</smiles>

Figure 4. Lysis of the Arg-esters by lipase.

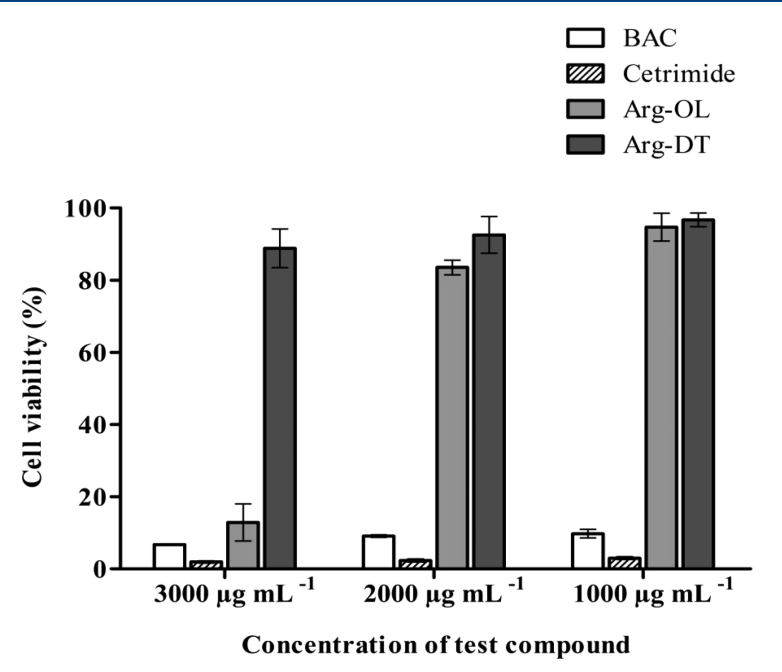

Figure 5. Percentage cell viability of Caco- 2 cells after $4 \mathrm{~h}$ of incubation with indicated compounds at $37{ }^{\circ} \mathrm{C}$, determined via the resazurin assay. Data represented as the mean $\pm \mathrm{SD}(n=3)$.

From cell viability data, the concentration causing $50 \%$ cell death (EC50 value) was also calculated for each sample as well as for controls: the lower the EC50, the higher is the toxicity of the compound. Both Arg-esters showed significantly higher EC50 values than controls. EC50 of Arg-OL was $2600 \mu \mathrm{g}$ $\mathrm{mL}^{-1}$, whereas EC50 of Arg-DT was $4500 \mu \mathrm{g} \mathrm{mL}^{-1}$. BAC and cetrimide showed EC50 of $20 \mu \mathrm{g} \mathrm{mL}^{-1}$ indicating higher toxicity. No toxicity data of other Arg-based compounds on Caco- 2 cells have been found in the literature. Data regarding the aquatic toxicity of some Arg-based compounds have been reported against Daphnia magna and Photobacterium phosphoreum in terms of IC50 and EC50 values in the range of 1.1-28 $\mu \mathrm{g} \mathrm{mL}^{-131}$

Moreover, the effect of Arg-esters on Caco-2 cell membrane fluidity was also determined using a DPH fluorescent probe. $\mathrm{DPH}$ is incorporated in the hydrophobic region of a lipid bilayer and is used to monitor the fluidity in this deeper region of the cell membrane. ${ }^{36}$ The knowledge of the fluid properties of biological membranes is important as these properties are crucial for various cell functions including signal transduction, cell growth, transportation across the membrane, and membrane enzymatic activities. Even a slight change in the fluidity of the membrane may cause disruptions in the membrane functions. ${ }^{37}$ Fluorescent anisotropy values and cell membrane fluidity are inversely correlated. The higher the fluorescent anisotropy, the lower is the membrane fluidity. ${ }^{36}$ The results of $r$ (DPH) for different concentrations of Argesters at various time points are represented in Figure 6. The

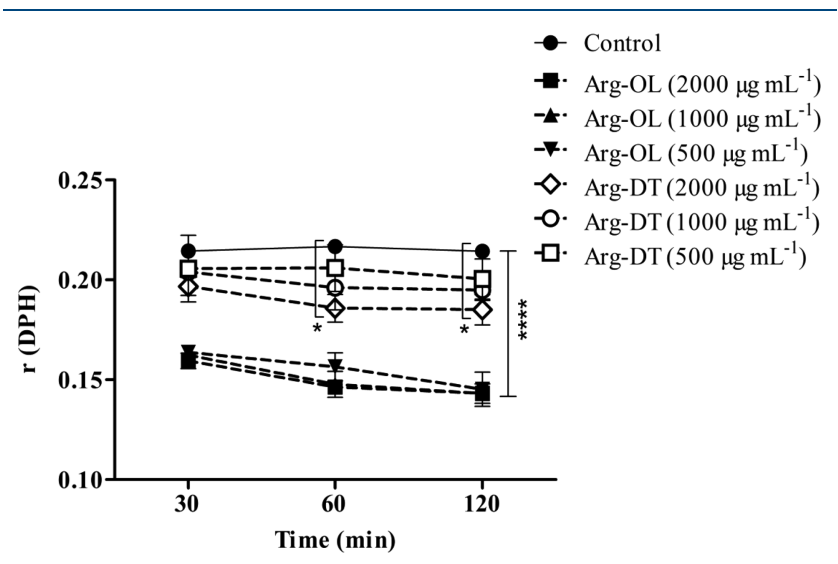

Figure 6. Effect of Arg-esters at indicated concentrations on the fluidity of the Caco-2 cell membrane at the hydrophobic region of a lipid bilayer. Solutions were prepared in HBSS $(10 \mathrm{mM}), \mathrm{pH} 7.4$, and mixed with an equal volume of the DPH-labeled cell suspension. HBSS mixed in an equal volume with the DPH-labeled cell suspension was used as a control. The anisotropy parameter $r$ values are denoted at indicated time points. Data represented as the mean \pm SD $(n=3),(* P<0.05, * * * * P<0.0001)$.

results show $>30 \%$ decrease in the anisotropy value within $2 \mathrm{~h}$ in the case of Arg-OL as compared to the control, indicating a decreased microviscosity of the lipid membrane. Changes in anisotropy were not significant in the case of Arg-DT $<1000$ $\mu \mathrm{g} \mathrm{mL} L^{-1}$. Results also show clearly the concentrationdependent increase in membrane fluidity due to interactions and incorporation of Arg-esters within membrane hydrophobic part. These interactions of Arg-esters can occur at their nontoxic concentrations $\left(500-2000 \mu \mathrm{g} \mathrm{mL}^{-1}\right)$. This effect of increasing membrane fluidity might be beneficial regarding membrane-associated cellular functions such as permeation improvement.

Red blood cells exhibit a comparatively fragile cell membrane. The hemolysis test is, therefore, a sensitive indicator for the cell membrane damaging effect in particular of amphiphilic compounds. ${ }^{38}$ Furthermore, as these Arg-esters might also be used as preservatives for injectable formulations that need to be blood-compatible, this assay is even of practical relevance. Although the red blood cell lysis assay is also used as an in vitro screening tool to predict potential ocular irritation, ${ }^{39}$ 
a direct correlation between hemolysis and cell membrane damage is, in most cases, not provided. Hemolytic data were obtained to estimate the disruption of cell membranes by cationic Arg-esters. As shown in Figure 7, the percentage of

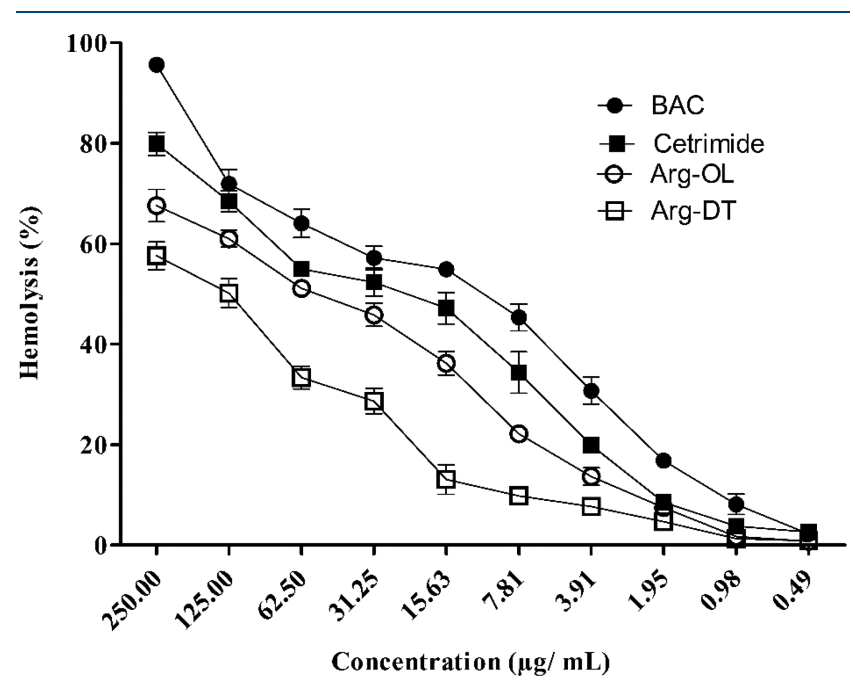

Figure 7. Hemolysis induced by the Arg-esters and well-established antimicrobials $\mathrm{BAC}$ and cetrimide at indicated concentrations. Samples were prepared in sterile Dulbecco's PBS, pH 7.4. Data represented as the mean $\pm \mathrm{SD}(n=3)$.

hemolysis is expressed as a function of concentration at $\mathrm{pH}$ 7.4. As compared to BAC and cetrimide, Arg-esters caused significantly less $(p<0.05)$ hemolysis. Like cytotoxicity studies on Caco- 2 cells, the cell membrane damaging effect of Arg-OL in the case of erythrocytes was also more pronounced than that of Arg-DT.

From hemolytic data, the concentration causing lysis of $50 \%$ red blood cells (HC50 value) was also calculated for each sample as well as for controls: the lower the HC50, the higher is the lysing ability of the compound. Both Arg-esters showed significantly higher $(p<0.05)$ HC50 values than controls. HC50 of Arg-OL was $60 \mu \mathrm{g} \mathrm{mL}^{-1}$, whereas HC50 of Arg-DT was even higher $\left(125 \mu \mathrm{g} \mathrm{mL}^{-1}\right)$. BAC and cetrimide showed significantly $(p<0.05)$ lower HC50 values that have been determined to be 12 and $23 \mu \mathrm{g} \mathrm{mL}{ }^{-1}$, respectively. HC50 values of both Arg-esters were also higher than other argininebased amphiphiles reported in the literature. HC50 of caproyl arginine methyl ester (CAM) and lauroyl arginine methyl ester (LAM) was 38.5 and $20.8 \mu \mathrm{g} \mathrm{mL} \mathrm{m}^{-1}$, respectively. Various double-chain/double-head arginine compounds, $\mathrm{N} \alpha, \mathrm{N} \omega$ bis $(\mathrm{N} \alpha$-acylarginine) $\alpha, \omega$-alkylendiamides, showed HC50 in the range of $8.7-110.5 \mu \mathrm{g} \mathrm{mL}^{-1}$. $^{31}$ Pianzo et al. determined the hemolytic activity of single-chain arginine surfactants with HC50 values in the range of $38-59 \mu \mathrm{g} \mathrm{mL}^{-1}$. $^{40}$ The results of hemolysis are in agreement with previous findings showing that the disruption of red blood cells decreases as the alkyl chain length increases. ${ }^{41}$

Although both Arg-esters showed a comparatively safe profile on Caco-2 and red blood cells, further in vitro and in vivo toxicity studies are necessary, as none of these tests can cover all toxicological aspects of preservatives.

3.5. Antimicrobial Properties of Arg-Esters. Arg-esters were evaluated regarding in vitro antimicrobial activity against Gram-negative bacteria (E. coli) and Gram-positive bacteria ( $S$. aureus, B. subtilis, and E. faecalis) according to international guidelines. $^{19}$ These bacterial strains are frequently used for antimicrobial testing. Antibacterial activity of BAC and cetrimide was also determined under the same experimental conditions serving as controls.

The disk diffusion method was used for the initial assessment of microbial susceptibility as it is a simple, rapid, and commonly used in vitro method for antimicrobial screening of new compounds. Clear growth inhibition zones against tested bacteria were observed for both Arg-esters, indicating their antibacterial activity. The observed zones of inhibition are shown in Table S-1, and the diameters of inhibition zones in $\mathrm{mm}$ are given in Table 1.

Table 1. Diameters of Growth Inhibition Zones against Indicated Microbes by the Disk Diffusion Method

\begin{tabular}{lrrcc} 
& \multicolumn{4}{c}{ zones of inhibition $(\mathrm{mm})$} \\
\cline { 2 - 5 } \multicolumn{1}{c}{ bacterial strain } & Arg- & Arg- & BL & cetrimide \\
Escherichia coli ATCC 25922 & 9 & 9 & 19 & 12 \\
Staphylococcus aureus ATCC 29213 & 19 & 16 & 21 & 19 \\
Bacillus subtilis ATCC 6633 & 16 & 18 & 23 & 19 \\
Enterococcus faecalis ATCC 19433 & 18 & 16 & 20 & 19
\end{tabular}

As it is not possible to quantify the diffused amount of antimicrobial agents from disk to agar medium, the disk diffusion method is not considered appropriate for determining the minimum inhibitory concentration (MIC). ${ }^{42}$ For determining the MIC, the microdilution method was used, which is comparatively time-consuming but robust and reliable. Both Arg-esters showed excellent antimicrobial activity against Gram-positive and Gram-negative bacteria. MIC results against all microbial strains are shown in Table 2.

Table 2. MIC Values of Arg-Esters, BAC, and Cetrimide against Indicated Bacteria Determined by the Microdiution Method

\begin{tabular}{lcccc} 
& \multicolumn{4}{c}{$\begin{array}{c}\text { minimum inhibitory concentration } \\
\left(\mu \mathrm{gL}^{-1}\right)\end{array}$} \\
\cline { 2 - 5 } \multicolumn{1}{c}{ bacterial strain } & $\begin{array}{c}\text { Arg- } \\
\text { OL }\end{array}$ & $\begin{array}{c}\text { Arg- } \\
\text { DT }\end{array}$ & BAC & cetrimide \\
Escherichia coli ATCC 25922 & 20 & 39 & 10 & 20 \\
Staphylococcus aureus ATCC 29213 & 10 & 10 & 5 & 5 \\
Bacillus subtilis ATCC 6633 & 5 & 5 & 5 & 5 \\
Enterococcus faecalis ATCC 19433 & 5 & 10 & 5 & 5
\end{tabular}

Arg-DT caused growth inhibition of E. coli at a concentration of $39 \mu \mathrm{g} \mathrm{mL}{ }^{-1}$. The MIC of Arg-DT against S. aureus and E. faecalis was $10 \mu \mathrm{g} \mathrm{mL}^{-1}$, whereas the MIC for B. subtilis was $5 \mu \mathrm{g} \mathrm{mL}^{-1}$. In contrast, Arg-OL inhibited the growth of E. coli and S. aureus at the concentration of $20 \mu \mathrm{g}$ $\mathrm{mL}^{-1}$ and $10 \mu \mathrm{g} \mathrm{mL}^{-1}$, respectively. The observed MIC of ArgOL for B. subtilis and E. faecalis was $5 \mu \mathrm{g} \mathrm{mL}^{-1}$.

The evaluation of the MIC for well-established antimicrobials BAC and cetrimide was also performed under the same experimental conditions. The MIC of BAC was $10 \mu \mathrm{g} \mathrm{mL}^{-1}$ against $E$. coli and $5 \mu \mathrm{g} \mathrm{mL}^{-1}$ against all Gram-positive bacteria (S. aureus, B. subtilis, and E. faecalis. Cetrimide inhibited bacterial growth of $E$. coli at a concentration of $20 \mu \mathrm{g} \mathrm{mL}^{-1}$, whereas the MIC of cetrimide against all tested Gram-positive bacterial strains was $5 \mu \mathrm{g} \mathrm{mL}{ }^{-1}$. The positive control (water 
with $10 \%(\mathrm{v} / \mathrm{v})$ DMSO) without any test compound did not lead to any bacterial growth inhibition.

According to these results, bacteria seem to be unable to cleave these Arg-esters in order to eliminate their antimicrobial activity. As Arg-esters were, in comparison to BAC and cetrimide, less toxic to Caco-2 cells (Figure 5) but showed antimicrobial activity at much lower concentration $(<50 \mu \mathrm{g}$ $\left.\mathrm{mL}^{-1}\right)$, it can be assumed that mammalian cells can more easily cleave these esters than bacteria. Moreover, the MIC of Argesters being in the range of $20-40 \mu \mathrm{g} \mathrm{mL}^{-1}$ against $E$. coli was lower than that of some previously reported amino acid-based antimicrobials. For example, lauroyl arginine methyl ester showed a MIC of $128 \mu \mathrm{g} \mathrm{mL} \mathrm{m}^{-1}{ }^{31}$ Furthermore, neither $\mathrm{N} \alpha$ octanoyl arginine ethyl ester ${ }^{43}$ nor various arginine-O-alkyl esters (octyl, decyl, and lauryl) were effective against E. coli at the highest tested concentration of $256 \mu \mathrm{g} \mathrm{mL}^{-1}$. $^{41}$ Arginine monoglycerides with alkyl chains of 10-14 carbons exhibited MICs from 64 to $128 \mu \mathrm{g} \mathrm{mL}^{-1}$, ${ }^{44}$ and various types of lysinebased cationic lipids showed MIC values from 166 to $331 \mu \mathrm{g}$ $\mathrm{mL}^{-1} \cdot{ }^{13}$ Arginine Gemini surfactants were only effective against Gram-positive bacteria at MICs from 28 to $90 \mu \mathrm{g}$ $\mathrm{mL}^{-1}$ with or without membrane cholesterol or dilauroylphosphatidylcholine. $^{45}$

Moreover, like all of these compounds, Arg-esters were found significantly more effective against Gram-positive bacteria than against Gram-negative E. coli. It might be due to the reason that Gram-negative bacteria have an additional outer hydrophilic layer acting as a strong permeability barrier. ${ }^{46}$ Comparatively higher antimicrobial activity of ArgOL than that of Arg-DT showed that antimicrobial properties were more likely dependent on the type of alkyl chain rather than the chain length or hydrophobicity. The presence of a double bond might affect the interaction with cell membranes in the case of Arg-OL ester. In a previous study with nonionic Schiff base surface-active compounds, a higher zone of inhibition in the case of linoleate derivatives with two double bonds in comparison to monounsaturated oleate derivatives was found underlining the crucial role of the degree of unsaturation in antimicrobial activity. ${ }^{47}$ A study on cationic lysine-based compounds demonstrated that biological properties are not only dependent on the type of hydrophobic chain but are also determined by the polar headgroup, its spatial position, and the cationic charge. ${ }^{13}$

\section{CONCLUSION AND FUTURE PROSPECTS}

For over half a century, cationic lipophilic compounds derived from quaternary ammonium compounds are being used as antimicrobials. $^{3}$ Due to poor biodegradation, hemolytic activity, and cytotoxicity, however, biomedical use of these cationic antimicrobials is regarded as problematic. ${ }^{6,7,9}$ Amino acid-based antimicrobials being less toxic and rapidly degraded in the human body deserve more attention. ${ }^{48}$ So this study was aimed to synthesize and evaluate novel cationic arginine-based esters with long carbon chains $\left(\mathrm{C}_{18}\right.$ and $\left.\mathrm{C}_{24}\right)$, regarding toxicity and antimicrobial properties in comparison to currently used antimicrobials. Newly formed Arg-esters showed significantly lower cytotoxicity and red blood cell lysis as compared to the well-established antimicrobials benzalkonium chloride and cetrimide. Furthermore, they were biodegradable and exhibited comparatively high antimicrobial properties. Based on these results, lipophilic arginine esters seem to be a promising alternative to well-established cationic lipophilic compounds used as preservatives in pharmaceutical and cosmetic formulations. Moreover, the need for developing novel antimicrobials is of great significance due to the emergence of resistant microbial strains in healthcare settings. ${ }^{49}$ Future research should consider testing these compounds regarding their safety profile in more detail before initiating a scale-up on the industrial level. These Arg-esters might first be used as a preservative in cosmetic and food products, followed by pharmaceuticals.

\section{ASSOCIATED CONTENT}

\section{Supporting Information}

The Supporting Information is available free of charge at https://pubs.acs.org/doi/10.1021/acs.molpharmaceut.0c00610.

${ }^{1} \mathrm{H}$ NMR spectra of OL (oleyl alcohol), Boc-Arg-OL (Boc-protected octadec-9-en-1-yl argininate), DT (2decyltetradecyl), and Boc-Arg-DT (Boc-protected 2decyltetradecyl argininate) in deuterated chloroform; FT-IR spectra of Arg-OL (octadec-9-en-1-yl argininate) and Arg-DT (2-decyltetradecyl argininate); ${ }^{1} \mathrm{H}$ NMR spectra of Arg-OL (octadec-9-en-1-yl argininate) and Arg-DT (2-decyltetradecyl argininate) in deuterated methanol; mass spectra of Arg-OL (octadec-9-en-1-yl argininate) and Arg-DT (2-decyltetradecyl argininate); TLC showing biodegradation of Arg-esters by lipase; data regarding inhibition zones against bacteria (PDF)

\section{AUTHOR INFORMATION}

\section{Corresponding Author}

Andreas Bernkop-Schnürch - Center for Chemistry and Biomedicine, Department of Pharmaceutical Technology, Institute of Pharmacy, University of Innsbruck, A-6020 Innsbruck, Austria; 이이. ord.o000-0003-4187-8277; Phone: +43-512-507-58601; Email: andreas.bernkop@ uibk.ac.at; Fax: +43-512-507-58699

\section{Authors}

Iram Shahzadi - Center for Chemistry and Biomedicine, Department of Pharmaceutical Technology, Institute of Pharmacy, University of Innsbruck, A-6020 Innsbruck, Austria

Aamir Jalil - Center for Chemistry and Biomedicine, Department of Pharmaceutical Technology, Institute of Pharmacy, University of Innsbruck, A-6020 Innsbruck, Austria

Mulazim Hussain Asim - Center for Chemistry and Biomedicine, Department of Pharmaceutical Technology, Institute of Pharmacy, University of Innsbruck, A-6020 Innsbruck, Austria; Department of Pharmaceutics, Faculty of Pharmacy, University of Sargodha, 40100 Sargodha, Pakistan

Andrea Hupfauf - Center for Chemistry and Biomedicine, Department of Pharmaceutical Chemistry, Institute of Pharmacy, University of Innsbruck, A-6020 Innsbruck, Austria

Ronald Gust - Center for Chemistry and Biomedicine, Department of Pharmaceutical Chemistry, Institute of Pharmacy, University of Innsbruck, A-6020 Innsbruck, Austria; (1) orcid.org/0000-0002-0427-4012

Philipp Alexander Nelles - Institute of Hygiene and Medical Microbiology, Department of Hygiene, Microbiology and Public Health, Medical University of Innsbruck, A-6020 Innsbruck, Austria

Ludwig Knabl - Institute of Hygiene and Medical Microbiology, Department of Hygiene, Microbiology and Public Health, Medical University of Innsbruck, A-6020 Innsbruck, Austria 
Complete contact information is available at:

https://pubs.acs.org/10.1021/acs.molpharmaceut.0c00610

\section{Notes}

The authors declare no competing financial interest.

\section{ACKNOWLEDGMENTS}

The authors would like to extend acknowledgment to the Austrian Agency for International Cooperation in Education and Research, Austria (ÖAD), Higher Education Commission of Pakistan (HEC), and the Austrian Research Promotion Agency FFG (West Austrian BioNMR 858017) for their assistance.

\section{REFERENCES}

(1) Oblak, E.; et al. Activity of gemini quaternary ammonium salts against microorganisms. Appl. Microbiol. Biotechnol. 2019, 103 (2), $625-632$.

(2) Zhao, T.; Sun, G. Synthesis and characterization of antimicrobial cationic surfactants: aminopyridinium salts. J. Surfactants Deterg. 2006, 9 (4), 325-330.

(3) McDonnell, G.; Russell, A. D. Antiseptics and disinfectants: activity, action, and resistance. Clin. Microbiol. Rev. 1999, 12 (1), 147-179.

(4) Perinelli, D. R.; et al. Quaternary Ammonium Leucine-Based Surfactants: The Effect of a Benzyl Group on Physicochemical Properties and Antimicrobial Activity. Pharmaceutics 2019, 11 (6), 287.

(5) Engebretsen, K. A.; et al. Allergic contact dermatitis caused by an antiseptic containing cetrimide. Contact Dermatitis 2015, 72 (1), 6061.

(6) Fortuna, G.; Cerchione, E.; Di Lorenzo, M. Cetrimide-induced oral mucositis: an unusual adverse drug reaction. Eur. J. Clin. Pharmacol. 2016, 72 (11), 1415-1416.

(7) Rath, A.; et al. In vitro effects of benzalkonium chloride and prostaglandins on human meibomian gland epithelial cells. Ann. Anat. 2019, 222, 129-138.

(8) Bilal, M.; Iqbal, H.M. An insight into toxicity and human-healthrelated adverse consequences of cosmeceuticals-a review. Sci. Total Environ. 2019, 670, 555.

(9) Mariotti, A. J.; Rumpf, D. A. Chlorhexidine-induced changes to human gingival fibroblast collagen and non-collagen protein production. J. Periodontol. 1999, 70 (12), 1443-1448.

(10) Rose, M. A.; et al. Chlorhexidine allergy in the perioperative setting: a narrative review. Br. J. Anaesth. 2019, 123 (1), e95-e103.

(11) Casey Laizure, S.; et al. The role of human carboxylesterases in drug metabolism: have we overlooked their importance? Pharmacotherapy: The Journal of Human Pharmacology and Drug Therapy 2013, 33 (2), 210-222.

(12) Stinchcomb, A. L.; et al. Straight-chain naltrexone ester prodrugs: diffusion and concurrent esterase biotransformation in human skin. J. Pharm. Sci. 2002, 91 (12), 2571-2578.

(13) Colomer, A.; et al. Cationic surfactants derived from lysine: effects of their structure and charge type on antimicrobial and hemolytic activities. J. Med. Chem. 2011, 54 (4), 989-1002.

(14) Perinelli, D. R.; et al. Quaternary ammonium surfactants derived from leucine and methionine: Novel challenging surface active molecules with antimicrobial activity. J. Mol. Liq. 2019, 283, 249-256.

(15) Shahzadi, I.; et al. Arginine-based cationic surfactants: Biodegradable auxiliary agents for the formation of hydrophobic ion pairs with hydrophilic macromolecular drugs. J. Colloid Interface Sci. 2019, 552, 287-294.

(16) Leonaviciute, G.; et al. Impact of lipases on the protective effect of SEDDS for incorporated peptide drugs towards intestinal peptidases. Int. J. Pharm. 2016, 508 (1-2), 102-108.
(17) Aricha, B.; et al. Differences in membrane fluidity and fatty acid composition between phenotypic variants of Streptococcus pneumoniae. J. Bacteriol. 2004, 186 (14), 4638-4644.

(18) Evans, B. C.; Nelson, C. E.; Yu, S. S.; Beavers, K. R.; Kim, A. J.; Li, H.; Nelson, H. M.; Giorgio, T. D.; Duvall, C. L.; et al. Ex vivo red blood cell hemolysis assay for the evaluation of $\mathrm{pH}$-responsive endosomolytic agents for cytosolic delivery of biomacromolecular drugs. J. Visualized Exp. 2013, 73, e50166.

(19) Methods for dilution: Antimicrobial susceptibility tests for bacteria that grow aerobically; approved standard, 10th ed; Clinical and Laboratory Standards Institute: Wayne, PA, 2015; Vol. 35.

(20) Pliška, V.; Schmidt, M.; Fauchère, J.-L. Partition coefficients of amino acids and hydrophobic parameters $\pi$ of their side-chains as measured by thin-layer chromatography. Journal of Chromatography $A$ 1981, 216, 79-92.

(21) Mata, J.; Varade, D.; Bahadur, P. Aggregation behavior of quaternary salt based cationic surfactants. Thermochim. Acta 2005, 428 (1-2), 147-155.

(22) Basu Ray, G.; Chakraborty, I.; Moulik, S. P. Pyrene absorption can be a convenient method for probing critical micellar concentration $(\mathrm{cmc})$ and indexing micellar polarity. J. Colloid Interface Sci. 2006, 294 (1), 248-254.

(23) Jiao, S.; Santos, A. P.; Panagiotopoulos, A. Z. Differences in free surfactant concentration and aggregation properties for amphiphiles with the same critical micelle concentration. Fluid Phase Equilib. 2018, 470, 126-133.

(24) Kümmerer, K.; Al-Ahmad, A.; Mersch-Sundermann, V. Biodegradability of some antibiotics, elimination of the genotoxicity and affection of wastewater bacteria in a simple test. Chemosphere 2000, 40 (7), 701-710.

(25) Epstein, S. P.; et al. Comparative toxicity of preservatives on immortalized corneal and conjunctival epithelial cells. J. Ocul. Pharmacol. Ther. 2009, 25 (2), 113-9.

(26) Stjerndahl, M.; van Ginkel, C. G.; Holmberg, K. Hydrolysis and biodegradation studies of surface-active esters. J. Surfactants Deterg. 2003, 6 (4), 319-324.

(27) Menon, G. K.; Grayson, S.; Elias, P. M. Cytochemical and biochemical localization of lipase and sphingomyelinase activity in mammalian epidermis. J. Invest. Dermatol. 1986, 86 (5), 591-597.

(28) Israeli, S.; et al. A mutation in LIPN, encoding epidermal lipase $\mathrm{N}$, causes a late-onset form of autosomal-recessive congenital ichthyosis. Am. J. Hum. Genet. 2011, 88 (4), 482-7.

(29) Stjerndahl, M.; Holmberg, K. Hydrolyzable nonionic surfactants: stability and physicochemical properties of surfactants containing carbonate, ester, and amide bonds. J. Colloid Interface Sci. 2005, 291 (2), 570-6.

(30) Wolf, J. D.; Kurpiers, M.; Baus, R. A.; Gotz, R. X.; Griesser, J.; Matuszczak, B.; Bernkop-Schnurch, A. Characterization of an amino acid based biodegradable surfactant facilitating the incorporation of DNA into lipophilic delivery systems. J. Colloid Interface Sci. 2020, 566, 234.

(31) Pérez, L.; et al. Biological properties of arginine-based gemini cationic surfactants. Environ. Toxicol. Chem. 2002, 21 (6), 12791285.

(32) Singh, A.; Tyagi, V. Arginine Based Novel Cationic Surfactants: A Review. Tenside, Surfactants, Deterg. 2014, 51, 202-214.

(33) Tatsumi, T.; et al. Novel hydrolyzable and biodegradable cationic gemini surfactants: 1,3-bis[(acyloxyalkyl)-dimethylammonio]-2-hydroxypropane dichloride. J. Surfactants Deterg. 2000, 3 (2), $167-172$.

(34) Perinelli, D. R.; et al. Correlation among chemical structure, surface properties and cytotoxicity of $\mathrm{N}$-acyl alanine and serine surfactants. Eur. J. Pharm. Biopharm. 2016, 109, 93-102.

(35) Riss, T. L., et al., Cell viability assays. Assay Guidance Manual [Internet]; Eli Lilly \& Company and the National Center for Advancing Translational Sciences, 2016

(36) Marczak, A. Fluorescence anisotropy of membrane fluidity probes in human erythrocytes incubated with anthracyclines and glutaraldehyde. Bioelectrochemistry 2009, 74 (2), 236-239. 
(37) ; Lenaz, G. Role of plasma membrane fluidity in the regulation of cellular activities. In Biomechanics of Cell Division.; Springer, 1987; pp 33-77.

(38) Nogueira, D. R; et al. Membrane-destabilizing activity of pHresponsive cationic lysine-based surfactants: role of charge position and alkyl chain length. Amino Acids 2012, 43 (3), 1203-1215.

(39) Sanchez, L.; et al. Potential irritation of lysine derivative surfactants by hemolysis and $\mathrm{HaCaT}$ cell viability. Toxicol. Lett. 2006, 161 (1), 53-60.

(40) Pinazo, A.; et al. Chemical structure and toxicity in argininebased surfactants. Arginine Amino Acid 2011, 125-142.

(41) Pinazo, A.; et al. Amino acid-based surfactants: New antimicrobial agents. Adv. Colloid Interface Sci. 2016, 228, 17-39.

(42) Balouiri, M.; Sadiki, M.; Ibnsouda, S. K. Methods for in vitro evaluating antimicrobial activity: A review. J. Pharm. Anal. 2016, 6 (2), 71-79.

(43) Singare, P.; Mhatre, J. Cationic Surfactants from Arginine: Synthesis and Physicochemical Properties. Am. J. Chem. 2012, 2, 186-190.

(44) Pérez, L.; et al. Monoglyceride surfactants from arginine: synthesis and biological properties. New J. Chem. 2004, 28 (11), $1326-1334$.

(45) Tavano, L.; et al. Role of aggregate size in the hemolytic and antimicrobial activity of colloidal solutions based on single and Gemini surfactants from arginine. Soft Matter 2013, 9, 306-319.

(46) Denyer, S. P.; Maillard, J. Y. Cellular impermeability and uptake of biocides and antibiotics in Gram-negative bacteria. J. Appl. Microbiol. 2002, 92, 35S-45S.

(47) Shafek, S. H.; et al. Antimicrobial potentials and surface activities of novel di-Schiff base nonionic surfactants bearing unsaturated hydrophobic tails. J. Mol. Liq. 2019, 290, 110986.

(48) Bordes, R.; Holmberg, K. Amino acid-based surfactants - do they deserve more attention? Adv. Colloid Interface Sci. 2015, 222, 79-91.

(49) Pereira, B. M. P.; Tagkopoulos, I. Benzalkonium chlorides: Uses, regulatory status, and microbial resistance. Appl. Environ. Microbiol. 2019, 85 (13), e00377-19. 